\title{
ALGUNAS PUNTUALIZACIONES \\ SOBRE «CATALUNYA, \\ LA FABRICA D'ESPANYA»
}

JORDI MALUQUER DE MOTES

La Revista de Historia Económica dedicaba en su penúltimo número (V, 3, otoño de 1987, pp. 623-628) unas cuantas páginas, escritas por Sebastián Coll Martín, a la exposición "Catalunya, la fábrica d'Espanya", que tuvo lugar en Barcelona a lo largo de varios meses del año 1985, y a su catálogo. Como coautor de una cosa y de la otra no puedo menos que agradecer los elogios allí expresados, pero también me siento obligado a formular más de una puntualización y a expresar mi discrepancia con el amigo Coll en algunos puntos. El hecho de formar parte del consejo asesor de la REvisTa, como también Jordi Nadal, convertiría en buenas las afirmaciones equivocadas del comentarista de producirse un silencio que se tomaría lógicamente por asentimiento.

1. Es de agradecer la amabilidad de Coll cuando alude al guión de la exposición y concluye que «los profesores Nadal y Maluquer de Motes deben prepararse excepcionalmente bien sus lecciones». Entiendo que la alabanza me está dedicada - de ahí mi reconocimiento-, puesto que el comentario no puede referirse al magisterio de $\mathrm{Nadal}$, avalado por muchas generaciones de economistas y por la totalidad de los historiadores económicos. Tengo la seguridad de que Coll no ignoraba ese detalle.

Sí desconoce, en cambio, la autoría del guión y ahí incurre en algunas confusiones de bastante tamaño. Contra lo que él afirma, el guión estaba reproducido íntegramente en los textos murales $y$, además, se recoge, también íntegro, en las páginas 163 a 181 del catálogo. Es verdad que «se presenta dividido en cinco capítulos», pero no lo es que tres de ellos hayan sido redactados por Nadal y dos por mí. Lo cierto es que los capítulos 1 y 3 fueron escritos por Nadal, mientras que yo me encargué de los apartados 2 , 3 y 5 .

Sorprende que Coll conozca el trabajo de «otros colaboradores de su Departamento», tanto más cuanto que para mí mismo esa información resulta completamente nueva. En los apartados que yo preparé no hubo jamás intervención de ningún tipo que no fuera totalmente mía. Por otra parte, Na- 
dal y yo mismo pertenecíamos entonces, y también ahora, a distintos Departamentos y a distintas Universidades, extremo que Coll hubiera podido averiguar leyendo el catálogo (p. 19). Para colmo, no hay en el guión ni una sola palabra que no sea nuestra. ¿De qué perversa musa le habrá llegado a Coll la inspiración para un "descubrimiento» tan imaginativo?

Mi sorpresa le resultará aún más comprensible al lector advertido, puesto que en las páginas 198 y 199 del catálogo se incorporó una ficha técnica detalladísima que no permite confusión de ninguna clase. Albert Carreras intervino, con mano nada «invisible» por cierto, en la preparación de mapas y gráficos y en los textos de los pies de las ilustraciones, así como en la confección de un audiovisual del que, naturalmente, no queda rastro en el catálogo. Por puntualizar, añadiré que este volumen no se editó sólo en castellano, «seguramente para poner la obra al alcance de un mayor número de personas», sino que se hicieron dos ediciones, la primera y mayor en lengua catalana.

2. En relación con el contenido específico del catálogo, señala Coll en su comentario de mis textos que tienen una umenor preocupación por el aspecto didáctico" que el de Nadal, constatación que me produce cierta perplejidad. Resulta siempre de bastante mal gusto cualquier mención de carácter comparativo, en este ámbito, puesto que fuerza a situar la réplica en terrenos un tanto resbaladizos. No voy a aceptar ese envite.

Debo añadir, además, que no entiendo muy bien su significado, a no ser que se refiera a algún desaliño en la composición de los textos. Aunque cometo errores a veces - como el propio Coll, supongo-, me gustaría conocer alguna de sus objeciones de una forma concreta. Quiero hacer constar, todavía, que pudo incorporarse alguna pequeña utraición" en la traducción desde el catalán, aunque la labor de Jordi Basté y Pilar Vélez, que no revisé, me parece bastante correcta.

Más contundencia, y mayor gravedad aparente, corresponde a su segunda reflexión de orden general en el sentido de que en cuanto a investigación nueva «tampoco se observan muchos signos de su existencia». Estoy seguro que Coll, a pesar de sus palabras, sabe distinguir entre un catálogo de una exposición y una obra de investigación. Los textos de nuestro catálogo no contienen notas a pie de página, indicación de fuentes, ni aparato erudito de ninguna clase, puesto que se limitan a recoger, para su divulgación, trabajos ya publicados en versiones modificadas al efecto. Así ocurre con el artículo de Jordi Nadal sobre "Los Bonaplata», que Coll no debería desconocer, puesto que se publicó en la mismísima Revista de Historia Económica (I, 1, primavera-verano de 1983, pp. 79-95).

Mis dos textos recogen fundamentalmente dos artículos. El primero contiene, en palabras de Coll, "una exposición de la teoría aceptada sobre los 
origenes de la manufactura catalana». Procede de Review. A Journal of the Fernand Braudel Center for the Study of Economics, Historical Systems, and Civilizations (X, 2, Fall 1986, pp. 315-344). Como tengo la absoluta seguridad de que ni Coll ni nadie pueden discutir la originalidad del planteamiento sobre la importancia del empleo de la energía hidráulica en la protoindustrialización y la incidencia de los derechos de propiedad del agua en ello, ni tampoco mi exclusiva paternidad, debo agradecer su calificación de teoría «aceptada». Viniendo de quien viene, y en el envoltorio que viene, valoro el calificativo como el mayor elogio que he recibido en toda mi carrera profesional. Confieso que el brevísimo plazo que media entre la publicación de mi texto - bien es cierto que había sido presentado verbalmente en la XV Settimana di Studi di Storia Economica de Prato, en 1983- y las frases de Coll mitigan mi conmoción por la supuesta «aceptación general» y me sugieren, más bien, un entusiasmo excesivo del autor de la reseña.

El segundo texto, según Coll, «desarrolla con mayor extensión el mismo esquema interpretativo que encontrábamos en Nadal», coincidencia que no debería sorprenderle y que me produce una gran satisfacción. Corresponde a un artículo publicado en el volumen La modernización económica de España, 1830-1930, que compiló Nicolás Sánchez-Albornoz (Madrid, Alianza Universidad, 1985, pp. 199-225), y ha sido traducido recientemente al inglés (Nueva York y Londres, New York University Press, 1987). Me pregunto cómo podíamos emprender la aventura de organizar una exposición de las dimensiones de "Catalunya», la fàbrica d'Espanya» sin compartir, por lo menos en lo esencial, una misma interpretación del fenómeno. El texto ha sido ya reseñado en la propia Revista dB Historia Económica (IV, 2, primaveraverano de 1986, pp. 278-282), en un tono quizá exageradamente elogioso.

3. Dicho esto, creo necesario consignar algo más sobre la supuesta ausencia de investigación nueva. Me parece de justicia obligada hacia nosotros mismos apuntar - ya que no lo hace Coll- que «Catalunya, la fàbrica d'Espanyas no fue otra cosa que la muestra final de una prolongada y compleja labor de investigación que nos llevó a ambos, conjuntamente o por separado, a escudriñar los más insólitos rincones de Cataluña, buscando - y encontrando- restos de talleres artesanales de las fargues o ferrerías del Pirineo, pequeñas centrales hidroeléctricas abandonadas hace muchas décadas, máquinas de todo tipo y las más variadas muestras de arqueología industrial. Sin duda, nuestra percepción de multitud de procesos tecnológicos salió ampliamente beneficiada de ello, pero también la de los visitantes de la exposición. Añadiré, de paso, que las más de cien mil personas que recorrieron el espléndido recinto barcelonés del Born no eran, desde luego, historiadores. ¡Afortunadamente!

No estará de más consignar que muchos particulares, empresas y orga- 
nizaciones de diverso tipo respondieron con auténtice entusiasmo a nuestros requerimientos de colaboración. El esfuerzo fue muy grande, pero también las respuestas $\mathrm{y}$, sin falsa modestia, los resultados. El patrimonio arqueológico catalán -el Museu de la Tècnica i de la Ciència, principalmentey la sensibilidad colectiva hacia las «lecciones del pasado» obtuvieron un refuerzo no pequeño.

Tengo para mí, y para quien quiera leerme aquí, que la exposición supuso una contribución nada desdeñable a la recuperación del aliento por el empeño innovador y por el cambio tecnológico, tan decaídos en los momentos más bajos de la crisis económica del país. Protagonista y testigo privilegiado de su gestación, interpreto que esa voluntad de incidencia en las actitudes sociales - que por un momento, felizmente ya superado, llevaron a nuestra juventud a soñar con alcanzar un puesto de oficial de tercera en algún oscuro despacho- estuvo presente desde el comienzo en nuestro propósito. Como también en el ánimo del alcalde barcelonés, Narcís Serra, que hizo suyo el proyecto antes de conocerlo. $Y$ en el del alcalde Pasqual Maragall, que lo heredó pero a la vez lo engrandeció. $\mathrm{Y}$ en el de los dirigentes de La Maquinista Terrestre y Marítima, legítima y directa depositaria de las viejas ambiciones de los Bonaplata-Esparó y tantos otros, que apoyaron decisivamente la realización de la muestra.

4. Coll dedica en su recensión un comentario especial a una de mis afirmaciones que le han «llamado la atención particularmente». Se trata de algo que no es nuevo para mí, puesto que el pasaje en cuestión parece haber «llamado la atención particularmente» a mucha gente, aunque a veces en sentidos contrapuestos. Veamos cuáles fueron las ideas tan escandalosas:

en teoría - -decía yo- había dos salidas: la primera, recurrir al mercado español, y la segunda, especializarse en la fabricación de productos de una clase o precio que permitiera penetrar con éxito en algunos segmentos específicos del mercado mundial, única posibilidad al alcance de las pequeñas economías europeas. Pero en la práctica, la segunda opción, "a la suiza", no existía, entre otras razones porque Cataluña no era, como Suiza, un país independiente, y su economía estaba sujeta a condicionamientos que le eran impuestos. (...) La alternativa de un crecimiento industrial basado, al menos parcialmente, en las exportaciones, no fue posible entre otros motivos - y principalmente- porque la vinculación a España le supuso un conjunto de problemas derivados de la ineficacia del sector agrario. 
Estos pasajes me han procurado todo tipo de críticas, desde las que me imputan un españolismo feroz hasta las que, como Coll, parece suponer aviesas intenciones escasamente patrióticas. El propio título de la exposición, al que no negaré cierta voluntad polémica, ha suscitado reacciones semejantes. No puedo contestar de una vez todo lo que se ha dicho sobre ello, aunque no pienso eludir el debate cuanro se plantee de una manera explícita.

Voy a concretarme, así, a las observaciones de Coll. Son dos y se sitúan, ambas, en un terreno muy estrecho al que yo en ningún caso me he querido reducir: el de la política arancelaria. Supone que mis argumentos se limitan al peso de la protección de otros sectores sobre las industrias catalanas y me reprocha no haberlo cuantificado. Lo más sorprendente es que su réplica peca exactamente del mismo supuesto error: tampoco entra en cuantificación de ninguna especie. La objeción se contesta sola. Voy a permitirme, sin embargo, añadir al bueno de Coll, y al lector interesado, la recomendación de un excelente artículo de Jordi Palafox Gamir, «Los límites de la modernización en España: la evolución económica entre 1892 y 1930" (Revista de Occidente, 83, abril de 1988, pp. 59-70). Es cierto que tampoco está cuantificado (bélas!), pero va siendo hora ya de advertir, a quienes pueda aprovechar, que uno no se convierte en historiador porque le hayan traído una calculadora los Reyes Magos.

Se me acusa, en segundo lugar, de simplificación por referirme desde Cataluña a la política proteccionista «como una responsabilidad exclusiva de otros». Es una imputación absolutamente gratuita. Coll es el único que distingue la política de los gobiernos españoles como algo «exclusivamente de otros». No hay en mi texto ni una sola frase que permita llegar a esa conclusión. De todos modo, por si le interesa el detalle al lector, añadiré que en la documentación de la propia empresa patrocinadora, La Maquinista Terrestre y Marítima, pueden encontrarse evidencias definitivas de que nunca en el siglo xix obtuvo la mínima protección necesaria para cumplir su primer objetivo fundacional: fabricar locomotoras. No estará de más añadir que, entre sus fundadores y dirigentes, La Maquinista reunía a la práctica totalidad de los «notables» del empresariado catalán.

Algunos historiadores han heredado de una literatura muy antigua el vicio de referirse continuamente al proteccionismo como algo universal en la España del siglo XIX, cuando es lo cierto que en algún ámbito se aplica la libertad absoluta de importar de forma invariable. Lo más evidente corresponde justamente a la franquicia a la importación de material ferroviario. De todos modos, es ya momento de referirse a algo más que a las tarifas de aduanas. Entiendo que más aisladora que los aranceles fue la política de transportes, al establecer un ancho de vía distinto del europeo -error que se ha conservado hasta hoy y que, de modo incomprensible, parece que va 
a consolidarse- Mis argumentos son, en todo caso, otros que los combatidos tan paladinamente por Coll. No es éste el lugar, ni cuento con el espacio necesario, para desarrollarlos otra vez. Quiero terminar, sin embargo, con el cierre de mi "polémico» párrafo: "para bien y para mal, en sus éxitos y en sus limitaciones, la industrialización de Cataluña no se puede explicar sin tener presente, en todo momento, su inserción en el conjunto de la economía española». Lo mantengo. 